\title{
Obituario
}

\section{Karl Popper}

\author{
Carlota Solé \\ Universitat Autònorna de Barcelona. Departament de Sociologia \\ 08193 Bellatera (Barcelona). Spain
}

La reciente muerte del filósofo Karl R. Popper (1902-1994) nos induce inexorablemente a recordar su larga y fructífera vida. La influencia de Popper en el pensamiento occidental de la segunda postguerra mundial ha sido decisivo tanto en el campo de la reflexión política y social como de la epistemologia. Sus obras (La lógica de la investigación, 1934; La sociedad abierta y sus enemigos, 1945; La miseria del historicismo, 1957; La lógica de la investigación cientifica, 1959; Sobre el origen del conocimiento y de la ignorancia, 1961; Conjeturas y refutaciones, 1969; Conocimiento objetivo: un enfoque evolucionista, 1972; El yo y su cerebro, 1977; Búsqueda sin término: una autobiografia intelectual, 1974; Postcriptum a la lógica de la investigación cientifica, 1982-1983; En busca de un mundo mejor, 1992) popularizaron el análisis de la sociedad liberal frente a las utopias inspiradas en Platón, Hegel o Marx; pero, sobre todo, significaron un eslabón imprescindible, aunque superado, en el avance de la filosofia de la ciencia.

La aportación de Popper arranca de su crítica y confrontación con sus amigos y colegas del llamado Círculo de Viena. Hacia 1907 los escritos y las enseñanzas del médico y fisiólogo Ennst Mach (1838-1916) contribuyeron a crear un clima de opinión en torno al núcleo de intelectuales y profesionales (Frank, Neurath, Hahn, Carnap, Gödel, Feigl entre otros) que pronto acabó llamándose el del positivismo lógico o empirismo lógico. Los positivistas lógicos desarrollaron una visión de la ciencia que tomó de la lógica y las matemáticas sus sistemas de representaciones simbólicas. De ahí, la importancia vital del lenguaje, es decir, de cómo se transmite el conocimiento científico y cómo se corresponde con la realidad. Este tema ha sido posteriormente tratado por las concepciones semánticas de la ciencia (Suppe, Sneed). Otra preocupación de los miembros del Círculo de Viena en los años 1930 fue la distinción entre lo científico y lo no científico, lo significativo y lo no significativo. Popper tercia en ese debate. El principio de verificación, a saber, que el significado de un enunciado o afirmación consiste en el método de su verificación, es substituido en los primeros escritos de Popper por el principio de validación y los criterios de de demarcación. Según este principio, un enunciado es significativo 
si potencialmente existe algún medio para probarlo, confirmarlo, o con mayor probabilidad, para falsarlo e invalidarlo si se observa o produce un único ejemplo disconforme con el enunciado universal. De ahí se sigue que la verificación de las hipótesis no se demuestra lógicamente, pero puede refutarse empíricamente.

La crítica al induccionismo parte de la idea de que no es posible demostrar la validez o inferir la verdad de un enunciado universal a partir de enunciados particulares, pero puede probar su falsedad, aun a partir de la verdad de los enunciados particulares o singulares. El conocimiento no proviene de los hechos observables exclusivamente (rechazo de la inducción). Los hechos no prueban necesariamente proposiciones teóricas (rechazo del justificacionismo). Una teoría, según Popper, se mantendrá en pie hasta que sea refutada, pero no podrá demostrarse nunca que sea verdadera, ni, incluso, probable. Lss teorías se fundamentarán en conjeturas y se formularán de forma provisional.

Para refutar una teoría se deriva a la evidencia empírica, aunque ésta por sí sola no pueda dar pruebas inequívocas, puesto que la misma percepción de los hechos no es contrastable entre sujetos observantes. El científico investigador decidirá qué conjunto de observaciones y experimentos realizará racionalmente para poder llegar a la refuración de su teoría. Estas decisiones racionales se tomarán de acuerdo con criterios externos del propio investigador y existentes en el seno de una comunidad científica, de acuerdo con el sistema de valores vigente. Kuhn hace especial hincapié en esa cuestión.

El falsacionismo se presenta como alternativa ante la dificultad de que, a partir de los enunciados observacionales verdaderos, se pueden formular leyes y teorías universales fundamentándose en deducciones lógicas, únicamente. La alternativa estriba en considerar que la ciencia es un conjunto de hipótesis que se proponen a modo de ensayo para describir o explicar de un modo preciso el comportamiento de algún aspecto del mundo o universo. La condición de partida es que para que una teoría pueda formar parte de la ciencia, las conjeturas formuladas como hipótesis han de ser falsables. Es decir, se puede encontrar un enunciado observacional o un conjunto de enunciados observacionales lógicamente posibles que sean incompatibles con una hipótesis. Una vez establecidos como verdaderos, estos enunciados falsarían la o las hipótesis. Las leyes y teorías universales no pueden probarse como verdaderas a partir de los enunciados observacionales, pero sí puede dedurcirse su falsedad. Es así como las falsaciones se convierten en puntos de partida fundamentales para el progreso de la ciencia. Son, pues, las inexactitudes y los errores, las pruebas y las nuevas comprobaciones de errores, lo que hace avanzar el conocimiento científico.

El criterio popperiano de falsabilidad y el método científico de conjeturas y refutaciones que propone nos lleva a reflexionar sobre el quehacer científico de los sociólogos afanados en inducir de la observación empírica de un estudio de caso, generalizaciones teóricas. Según Popper, la observación y el experimento no pueden nunca probar la verdad de una teoría científica, pero pueden refutarla. La investigación sociológica constata a posteriori los fenó- 
menos que estudia pero no puede adelantar hipótesis audaces ni predecir esos fenómenos, para luego probar empiricamente su falsedad.

Sin embargo, a pesar de haber sido superado por desarrollos posteriores de la filosofía de la ciencia (Lakatos, Feyerabend, Kuhn; Stegmüller, Moulines y otros) y por el propio avance de las ciencias que Popper aceptaba como tales (ciencias que admiten teorías con anomalías o excepciones, teorías corroboradas que no se plantean como aproximación a la verdad, etc.) la aportación epistemológica y de filosofía política de Popper es vigente todavía para la sociología y la ciencia política. Avanzar paso a paso en el conocimiento de la realidad social bajo la égida de una casi ingeniería social, rechazar las formas de certeza absoluta inspiradas en planteamientos globalizadores que hacen abstracción de las limitaciones humanas que ya Hobbes tuvo en consideración, limitarse a ejercer la prueba y el error antes de llegar a conclusiones contundentes, son quizá algunas de las pautas que los científicos sociales han interiorizado en su cotidiana tarea investigadora sin percatarse de la remota influencia de Popper. Más explícita es la vigencia de este gran filósofo en la reflexión política. El análisis de las tendencias totalitarias implícitas, según Popper, en el pensamiento de Platón, Hegel y Marx, ayuda a relativizar sobre la idealización del poder del pueblo y a reconsiderar la democracia como el menor de los malos sistemas políticos. El escepticismo de Popper se desvanece, sin embargo, en la creencia del papel decisivo del conocimiento en la evolución de las sociedades democráticas, fundamentalmente libres y respetuosas de la individualidad. Con todo, su defensa del racionalismo crítico le lleva a negar cualquier predicción sobre el progreso del conocimiento, como tampoco existen leyes que determinen la historia humana. Y, a pesar de tantas aparentes incertidumbres, Popper acertó en adelantarse en la posible explicación de algunos cambios en el orden internacional, inimaginables para muchos de nosotros, en los años en que escribió sus obras más conocidas ( La sociedad abierta y sus enemigos, La miseria del historicismo). Como otros grandes filósofos y pensadores sociales, aunque superado en algunas de sus apuestas, Popper tiene a partir de su muerte un lugar destacado en el panteón del conocimiento científico. 